\title{
PREPARATION WITH MODELING AND THEORETICAL PREDICTIONS OF MECHANICAL PROPERTIES OF FUNCTIONALLY GRADED POLYETHYLENE/CLAY NANOCOMPOSITES
}

\author{
Mohhamad H. Yas, Mahdi K. Khorramabadi \\ Department of Mechanical Engineering, Razi University, Kermanshah, Iran \\ e-mail:yas@razi.ac.ir; mehdi_karami2001@yahoo.com
}

\begin{abstract}
This paper presents preparation with modeling and theoretical predictions of mechanical properties of compatibilized functionally graded and uniform distribution polyethylene/modified montmorillonite nanocomposites manufactured by solution and melt mixing techniques. The morphology is studied by Scanning Electron Microscopy (SEM) and comparisons are made between two techniques. Young's modulus of nanocomposites for functionally graded and uniform distributions is calculated using a genetic algorithm and is then compared with the results of other theoretical prediction models mentioned in the literature as well as experimental results. It is found that the melt mixing technique is the preferred preparation method, and the results obtained from the theoretical predictions of genetic algorithm procedure are in good agreement with the experimental ones.
\end{abstract}

Keywords: functionally graded material, nanocomposites, solution technique, melt mixing technique, genetic algorithm theory

\section{Introduction}

Nanocomposites have attracted attention in the recent years because of their improved mechanical, thermal, solvent resistance and fire retardant properties compared to the pure or conventional composite materials. There has been growing interest in polymer/nanoclay nanocomposites in recent years because of their outstanding properties at low loading levels as compared with conventional composites. It has been observed that adding small quantities of nanoclay to some thermoplastics as a reinforcing filler to form nanocomposite materials has not only led to more improved mechanical and thermal properties, but also to enhancement of dielectric strength and partial discharge resistance (Kawasumi et al., 1997; Tan and Yang, 1998; Han et al., 2001; Kornmann et al., 2001; Utracki and Kamal, 2002; Hotta and Paul, 2004; Zhao and He, 2006; Awaji et al., 2009; Chen and Chen, 2009; Kim et al., 2009). As reported in several previous papers (Avila et al., 2008; Nam et al., 2001; Hrachova et al., 2013; Pakdaman et al., 2013; Grigoriadi et al., 2012), some continuum-mechanics based theoretical models have been proposed to predict mechanical properties of polymer/clay nanocomposites. Fornes and Paul (2003) applied the Halpin-Tsai and Mori-Tanaka reinforcement theories to predict the modulus of nylon based nanocomposites. The modulus obtained using Mori-Tanaka calculation increased with nanoclay reinforcement as predicted. The Halpin-Tsai formula gave higher values to the modulus but could still be used to predict its magnitude.

Some efforts have been focused on the modeling of mechanical properties of nanoclay-reinforced polymer composites (Sheng et al., 2004) and nanoparticle-reinforced polymer composites (Smith et al., 2002; Brown et al., 2003). Those modeling efforts have demonstrated the need for the development of a model that would predict mechanical properties of nanoparticle/polyimide composites as a function of nanoparticle size and weight fraction as well as the molecular structure of the nanoparticle/polyimide interface. Although experimental-based research 
can ideally be used to determine structure-property relationships of nanostructured composites, experimental synthesis and characterization of nanostructured composites demands making use of sophisticated processing methods and testing equipment, which may result in exorbitant costs. To this end, computational modeling techniques for determination of the mechanical properties of nanocomposites have proven to be very effective (Liu and Chen, 2003; Chen and Liu, 2004; Avila et al., 2006; Haque and Shamsuzzoha, 2003; Isik et al., 2003; Thilly et al., 2009; Dong et al., 2008; Song and Youn, 2006). Genetic algorithms are a family of computational models inspired by evolution. These algorithms encode a potential solution or a specific problem on a simple chromosome-like data structure and apply recombination operators to these structures so as to preserve critical information. Genetic algorithms are often viewed as function optimizers, although the range of problems to which genetic algorithms have been applied is quite broad.

Functionally Graded Materials (FGMs) are inhomogeneous composite materials with gradient compositional variation of the constituents (e.g., metal and ceramic) from one surface of the material to the other, which results in continuously varying material properties. The materials are intentionally designed in such a way that they possess desirable properties for specific applications. Shen $(2009,2011)$ suggested that the interfacial bonding strength can be improved through the use of a graded distribution of CNTs in the matrix and examined nonlinear bending behavior of simply supported, functionally graded nanocomposite plates reinforced by single walled carbon nanotubes subjected to a transverse uniform or sinusoidal loading in thermal environment. He also investigated post-buckling of nanocomposite cylindrical shells reinforced by SWCNTs subjected to axial compression in thermal environment and showed that the linear functionally graded reinforcements can increase the buckling load. Shen and Xiang (2012) investigated large amplitude vibration behavior of FG-CNTRC cylindrical shells in thermal environments. They assumed that the material properties of CNTRCs were temperature-dependent and solved the equations of motion by an improved perturbation technique to determine nonlinear frequencies of the CNTRC shells.

The present work deals with the preparation and modeling with theoretical predictions of mechanical properties of compatibilized functionally graded and uniform distribution polyethylene/low density polyethylene (LDPE)/modified montmorillonite (MMT) nanocomposites prepared by both solution and melt mixing techniques. The morphology is studied by Scanning Electron Microscopy (SEM) and comparisons are made between the two techniques and then between functionally graded polyethylene/clay nanocomposites with the uniform ones. By using the genetic algorithm procedure, Young's modulus of nanocomposites for functionally graded and uniform distributions is calculated and then is compared with the results of other theoretical predictions models mentioned in the literature and the experimental results. It is found that the melt mixing technique is the preferred method for preparation the functionally graded and uniform distribution polyethylene/clay nanocomposites. Finally, it is shown that the results obtained from the genetic algorithm approach are in good agreement with the experimental ones.

\section{Experimental}

\subsection{Materials}

The polymer matrix used in this study was a linear low-density polyethylene with the trade name LL209AA from Arak Petrochemical Co. (Iran), with melt flow index (MFI) of $0.9 \mathrm{~g} / 10 \mathrm{~min}$ and density of $\rho=0.92 \mathrm{~g} / \mathrm{cms}$. The nanofiller were K10 montmorillonite from Sigma-Aldrich, Germany. Also, the polyethylenglycol employed in this study was polyethylenglycol 40 from Merk-KGaA, Germany. 


\subsection{Processing}

\subsubsection{Melt mixing technique for uniformed distribution (UD)}

An internal mixer from Brabender, Germany (model WHT 55), with roller type rotors and mixer capacity of $55 \mathrm{~cm}^{3}$ was used for preparing nanocomposites samples. The nano clay (MMT) was dried at $40^{\circ} \mathrm{C}$ in a vacuum oven for a minimum of $48 \mathrm{~h}$. Low density polyethylene (LDPE) and polyethylenglycol were added to the nanoclay. All materials were manually premixed before introduction into the mixer. The extrusion temperature was set at $140-180^{\circ} \mathrm{C}$ from the feeder to the die.

\subsubsection{Solution technique for uniformed distribution (UD)}

The nanoclay (MMT) was dried at $40^{\circ} \mathrm{C}$ in the vacuum oven for a minimum of $48 \mathrm{~h}$. Low density polyethylene (LDPE) and toluene solution were added to the nanoclay. The mechanical mixture was stirred for $30 \mathrm{~min}$ at room temperature. After $30 \mathrm{~min}$ of mechanical stirring, the suspension was treated with ultrasound for 20 min. After stirring, the suspension was distilled. The ultrasonic stirring from Hielscher, Germany (model UP400S), was used to ultrasound the suspension.

\subsubsection{Melt mixing technique for functionally graded distribution (FGD)}

After the melt mixing procedure, the products were then compressed and molded into sheets by an electrically heated hydraulic press. The thickness of every sheet was $1 \mathrm{~mm}$ and four sheets with different nanoparticles weight fractions (pure, 1 wt. $\%, 3$ wt. $\%$ and 5 wt. $\%$ ) were employed to form functionally graded nanocomposite. The processing of melt mixing technique for functionally graded distribution is presented in Fig. 1.

(a)

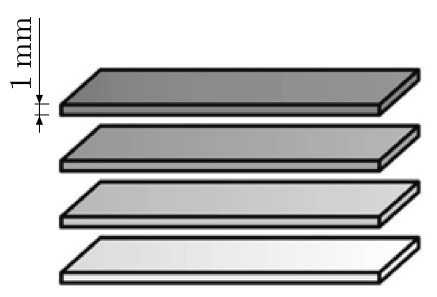

(b)

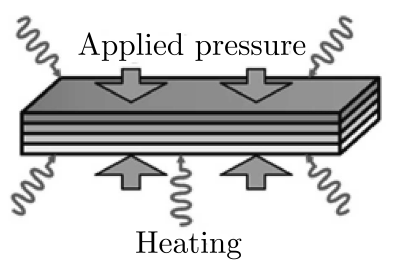

(c)

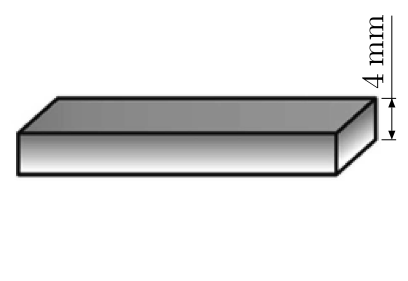

Fig. 1. Processing of melt mixing technique for functionally graded distribution: (a) primary set of nanocomposite sheets with different nanoparticle fractions, (b) processing the FG nanocomposite,

(c) fabricated FG nanocomposite

\subsection{Scanning electron microscopy (SEM) analysis}

The morphology of nanocomposite cross section samples was investigated using a SERON AIS2300C scanning electron microscope. The initial sample preparing process was carried out by a gold-coater chamber. Figure $2 \mathrm{a}$ is the SEM photography of the nanocomposite for uniform distribution prepared by the solution technique and Fig. 2b is the SEM image of the nanocomposite for uniform distribution prepared by the melt mixing technique.

Figure 2a shows that the morphology for the solution technique is not homogeneous, which reveals a poor intercalated/exfoliated structure. However, when the melt mixing technique was employed and a compatibilizer was added (Fig. 2b), it was observed that the density and size of the aggregates decreased, which indicated that the dispersion of nanoclays within the polymer matrix was much better. The comparisons between Fig. 2a and Fig. 2b show that the adhesion of the particles of nanoclay and polymer in the presence of the compatibilizer is improved. The 
(a)

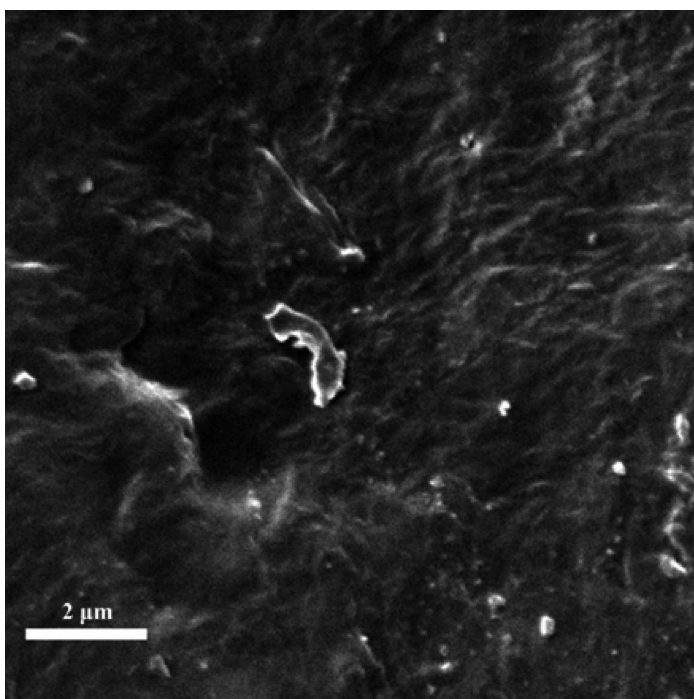

(b)

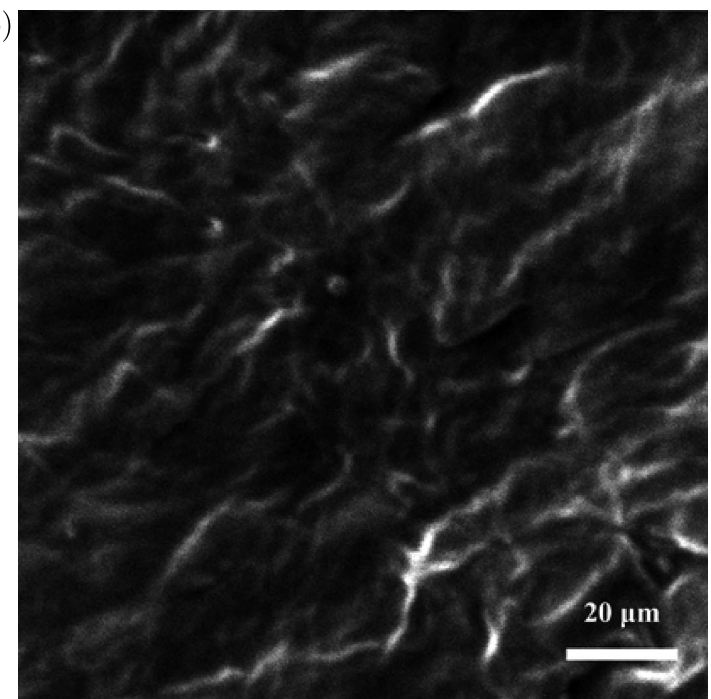

Fig. 2. SEM image of nanocomposite prepared by (a) solution technique and (b) melt mixing technique for uniform distribution

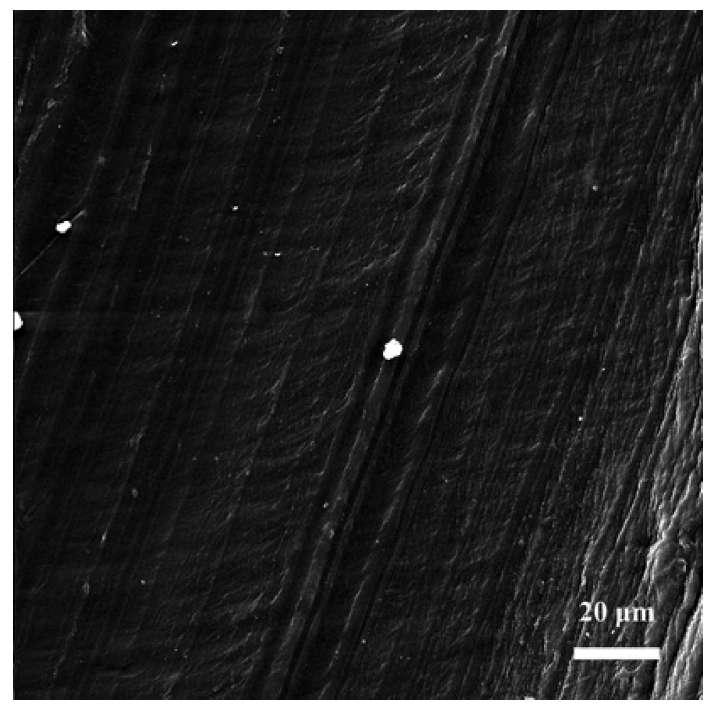

Fig. 3. SEM image of nanocomposite prepared by melt mixing technique for functionally graded distribution

morphology of nanocomposites cross section samples for functionally graded distribution was investigated by a TESCAN MRIA3 SEM after being coated with gold. Figure 3 is the SEM image of the nanocomposite for functionally graded distribution prepared by the melt mixing technique. It seems that the dispersion of nanoclay varies smoothly and continuously from one surface to the other.

\subsection{Mechanical properties}

The tensile properties were evaluated according to ASTM D638 using dumbbell-shaped samples and a Gotech universal testing machine (Model GT-AI5000L) tensile tester with a crosshead speed of $50 \mathrm{~mm} / \mathrm{min}$. The material compositions of the nanocomposites are listed in Table 1.

Figure 4a illustrates the effect of nanoparticles with different weight fractions on the elastic modulus. As noticed, the elastic modulus begins to increase up to 5 wt. $\%$ of nanoclay. As the 
Table 1. Sample compositions

\begin{tabular}{|c|c|c|c|}
\hline Sample & $\begin{array}{c}\text { LDPE } \\
{[\mathrm{wt} \%]}\end{array}$ & $\begin{array}{c}\text { Compatibilizer } \\
{[\text { wt\%] }}\end{array}$ & $\begin{array}{c}\text { MMT } \\
{[\text { wt\%] }}\end{array}$ \\
\hline \hline 1 & 85 & 15 & - \\
\hline 2 & 82 & 15 & 3 \\
\hline 3 & 80 & 15 & 5 \\
\hline 4 & 78 & 15 & 7 \\
\hline
\end{tabular}

clay weight fraction exceeds 5 wt.\%, the elastic modulus levels off, but for functionally graded distribution, the elastic modulus is generally larger than the corresponding values for uniformed distribution of the nanoclay.

(a)

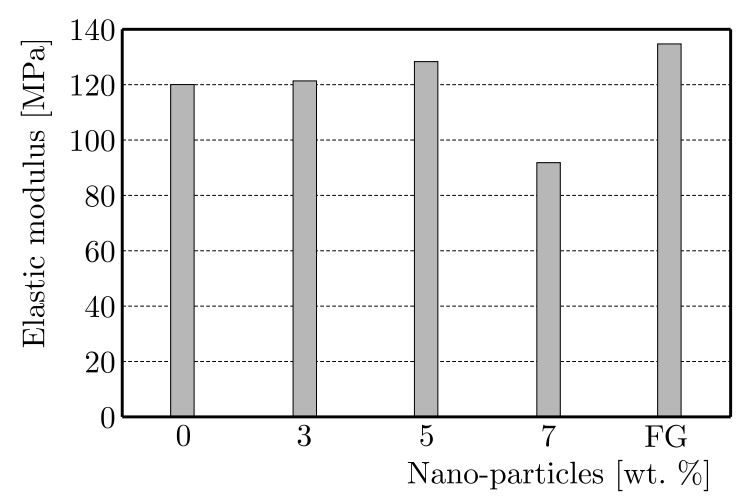

(b)

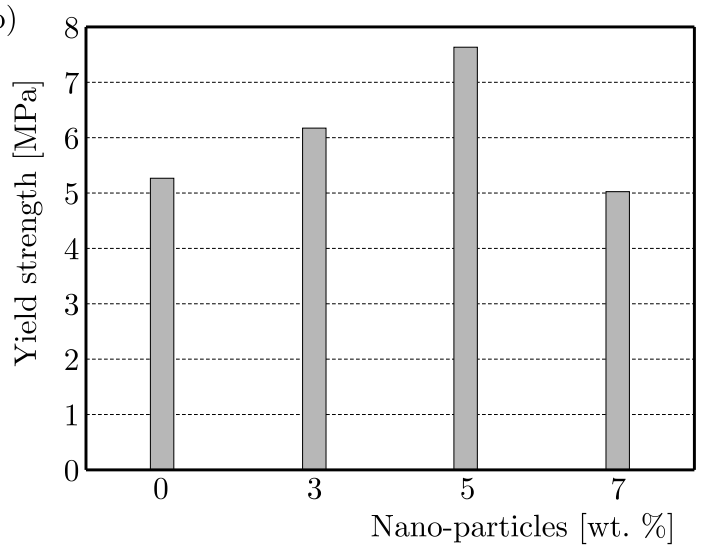

Fig. 4. The effect of nanoparticles with different weight fractions on (a) elastic modulus and (b) yield strength

Figure $4 \mathrm{~b}$ illustrates the effect of nanoparticles with different weight fractions on yield strengths. As observed, the yield strengths begin to increase up to $5 \mathrm{wt} . \%$ of nanoclay. As the weight fraction of clay exceeds $5 \mathrm{wt} . \%$, the yield strengths level off.

\section{Modeling}

\subsection{Theoretical predictions}

GA is an unorthodox search or optimization algorithm which was first suggested by John Holland in his book Adaptation and Artificial Systems (Holland, 1975). As the name suggests, the GA was inspired by processes observed in natural evolution. The GA method searches for the best alternative (in the sense of a given fitness function) through chromosome evolution. In this paper, the $1-R_{a d j}^{2}$ is introduced as the fitness function which is to be minimized. $R_{a d j}^{2}$ is the accuracy criterion of an arbitrary mechanical property function (such as Young's modulus). $R_{a d j}^{2}$ is defined as a process which is demonstrated below. The mechanical property is a function of nanoclay weight percent and $R_{a d j}^{2}$ is a function of coefficients which are introduced below. $M_{i}$ is considered as the mechanical properties and $W$ as the nano clay weight percent. $M_{1}, M_{2}, M_{3}$ and $M_{4}$ are Young's modulus, yield stress, ultimate strength and elongation at break, respectively. The $M_{i}$ is expressed as a polynomial function of $W$ as follows

$$
M_{i}=\sum_{j=0}^{4} a_{j i} W^{j}
$$


Now, the coefficients $a_{j i}$ are found by maximizing the accuracy of the polynomial function. The equations can be written as:

$$
R_{a d j}^{2}=1-\frac{V A R_{E}}{V A R_{T}}
$$

in which

$$
\begin{array}{rlrl}
V A R_{E} & =\frac{S S_{\text {Err }}}{n-k-1} & V A R_{T} & =\frac{S S_{\text {Tot }}}{n-1} \\
S S_{\text {Tot }} & =\sum_{i=1}^{n}\left(y_{i}-\bar{y}\right)^{2} & S S_{E r r} & =\sum_{i=1}^{n}\left(y_{i}-M_{i}\right)^{2} \quad \bar{y}=\frac{1}{n} \sum_{i=1}^{n} y_{i}
\end{array}
$$

and

$$
M_{i}(W)=a_{0 i}+a_{1 i} W+a_{2 i} W^{2}+a_{3 i} W^{3}
$$

In these equations, $n=4$ is the number of experiments and $k=0$ is the number of duplicated experiments and $y_{i}$ show the experimentally measured mechanical properties. After minimization of $1-R_{a d j}^{2}$ via MATLAB, the factors $a_{j i}$ are obtained after approximately 40 generations.

\subsection{Einstein's model}

One of the earliest models developed to predict mechanical properties of composites is Einstein's model (Einstein, 1956)

$$
\frac{E_{c}}{E_{m}}=1+2.5 \phi_{f}
$$

where $E_{c}$ and $E_{m}$ are the moduli of the composite and matrix, respectively. $\phi_{f}$ is the volume fraction of the filler in the matrix.

\subsection{Guth and Gold model}

The reinforcing effect of spherical colloidal fillers on elastomers was studied by Guth and Gold, and the modulus is given by equation (Guth, 1945)

$$
E_{c}=E_{m}\left(1+2.5 \phi_{f}+14.1 \phi_{f}^{2}\right)
$$

where $E_{c}$ and $E_{m}$ are the moduli of the composite and matrix, respectively. $\phi_{f}$ is the volume fraction of the filler in the matrix. The conversion of weight fractions of nanoclay to volume fractions is shown in Table 2 .

Table 2. Conversion of weight fractions of nanoclay to volume fractions

\begin{tabular}{|c|c|}
\hline $\begin{array}{c}\text { Volume fraction } \\
\text { of nanoclay }\end{array}$ & $\begin{array}{c}\text { Weight fraction } \\
\text { of nanoclay }\end{array}$ \\
\hline \hline $3 \%$ & $1.44 \%$ \\
\hline $5 \%$ & $2.4 \%$ \\
\hline $7 \%$ & $3.36 \%$ \\
\hline
\end{tabular}




\subsection{Mori-Tanaka model}

A combination of the Mori-Tanaka mean stress concept and the eigenstrain idea of Eshelby's inclusion model was used by Tandon and Weng (1984) to determine the overall elasticity tensor of the nanocomposite materials, assuming that either of the mixture and inclusions (e.g., discontinuous fibers/flakes/nanoparticles) are isotropic or transversely isotropic. For a material reinforced by ellipsoidal particles aligned in the longitudinal direction, the longitudinal modulus may be determined as

$$
\frac{E_{1} 1}{E_{m}}=\frac{1}{1+\frac{1}{A} f_{p}\left(A_{1}+2 \nu_{m} A_{2}\right)}
$$

where the subscripts $p$ and $m$ stand for the particles and the matrix, respectively. $\nu_{m}$ is Poisson's ratio of the matrix and $f_{p}$ are the inclusion particles volume fraction. The constants $A$ and $A_{i}$ can be calculated from the matrix/particle properties and components of Eshelby's tensor $H_{i j k l}$ (Sheng et al., 2004; Eshelby, 1961; Taya, 1981; Taya and Mura, 1981) which depend on the particle aspect ratio and dimensionless elastic constants of the matrix.

\section{Results and discussion}

Obtaining the $a_{j i}$ coefficients, Young's modulus can be expressed as a function of the nanoclay weight percent as follows

$$
E=-3.401 w+4.97 w^{2}-0.677 w^{3}+105.338
$$

Here, $w$ is the nanoclay weight percent. To investigate correctness of the present results, comparison studies are carried out for Young's modulus of uniform distribution nanocomposites which are presented in Table 3 .

Table 3. Comparison of Young's modulus for uniform distribution nanocomposites

\begin{tabular}{|c|c|c|c|c|c|}
\hline $\begin{array}{c}\text { Nano clay } \\
\text { weight } \\
\text { percent }\end{array}$ & $\begin{array}{c}\text { Einstein's } \\
\text { predictions } \\
{[\mathrm{Mpa}]}\end{array}$ & $\begin{array}{c}\text { Guth and Gold's } \\
\text { predictions } \\
{[\mathrm{Mpa}]}\end{array}$ & $\begin{array}{c}\text { Mori-Tanaka } \\
\text { predictions } \\
{[\mathrm{Mpa}]}\end{array}$ & $\begin{array}{c}\text { Theoretical } \\
\text { predictions } \\
{[\mathrm{Mpa}]}\end{array}$ & $\begin{array}{c}\text { Experimental } \\
\text { results } \\
{[\mathrm{Mpa}]}\end{array}$ \\
\hline \hline pure & 105.338 & 105.338 & 105.338 & 105.338 & 105.338 \\
\hline $3 \%$ & 109.130 & 109.438 & 126.362 & 121.586 & 121.582 \\
\hline $5 \%$ & 111.658 & 112.513 & 132.715 & 127.958 & 127.939 \\
\hline $7 \%$ & 114.186 & 115.863 & 139.412 & 92.850 & 92.795 \\
\hline
\end{tabular}

The compression between theoretical predictions and the experimental data shows high accuracy of the present analysis. Equation (4.1) can be used to derive the suitable relation for Young's modulus of the functionally graded distribution. The specimen with functionally graded distribution consists of four perfectly bonded sheets with a total thickness of $4 \mathrm{~mm}$. Each sheet has $1 \mathrm{~mm}$ thickness with different nanoparticles weight fractions (pure, $1 \mathrm{wt} . \%, 3 \mathrm{wt} . \%$ and 5 wt.\%). Young's modulus can be written as

$$
E(z)=-3.401(2 z+\operatorname{sgn}[z])+4.97(2 z+\operatorname{sgn}[z])^{2}-0.677(2 z+\operatorname{sgn}[z])^{3}+105.338
$$

As mentioned before, Young's modulus is assumed to vary as a function of the thickness coordinate $z(0 \leqslant z \leqslant 4)$. Equation $(4.2)$ can be verified via employing static analysis of the functionally graded nanocomposite beam under a transverse load. It is considered as a functionally graded nanocomposite beam as shown in Fig. 5. 


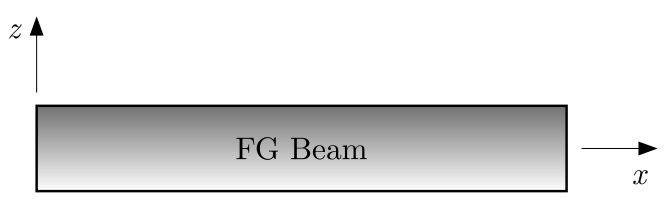

Fig. 5. Schematic of the problem studied

The thickness, length, and width of the beam are denoted, respectively, by $h, L$, and $b$. The position of neutral surface can be determined as (Yaghoobi and Fereidoon, 2010):

$$
h_{0}=\frac{\int_{-h / 2}^{h / 2} E(z) z d z}{\int_{-h / 2}^{h / 2} E(z) d z}
$$

In the Euler-Bernoulli theory, the differential equation of deflection can be expressed as (Yaghoobi and Fereidoon, 2010)

$$
\frac{d^{2} w}{d x^{2}}=\frac{M(x)}{D}
$$

where $D$ denotes bending rigidity of the FG nanocomposite beam defined by (Yaghoobi and Fereidoon, 2010)

$$
D=\int_{-h / 2}^{h / 2} b E(z)\left(z-h_{0}\right)^{2} d z
$$

Boundary conditions for simply supported and cantilever beams are

$$
\begin{aligned}
& w=0 \quad \text { at } \quad x=0, l \\
& w=0 \quad \wedge \quad \frac{d w}{d x}=0 \quad \text { at } \quad x=0, l
\end{aligned}
$$

By integrating Eq. (4.4) and then applying boundary conditions, Eqs. (4.6), one can easily obtain deflection of the beam under the transverse load. For static analysis of the functionally graded nanocomposite beam under the transverse load, the beam apparatus from TQ, England (Model SM1004), was used for deflection test. The test specimen had a rectangular cross section $(20 \times 4) \mathrm{mm}^{2}$ and a length of $15 \mathrm{~cm}$. The load magnitude for both boundary conditions was $0.54 \mathrm{~N}$. The comparison between theoretical and experimental data for the deflection of the functionally graded distribution nanocomposites is shown in Table 4.

Table 4. Compression between theoretical and experimental data for deflection

\begin{tabular}{|l|c|c|c|c|}
\hline $\begin{array}{c}\text { Boundary } \\
\text { condition }\end{array}$ & $\begin{array}{c}\text { Load } \\
\text { position } \\
x[\mathrm{~cm}]\end{array}$ & $\begin{array}{c}\text { Deflection mea- } \\
\text { suring position } \\
x[\mathrm{~cm}]\end{array}$ & $\begin{array}{c}\text { Theoretical } \\
\text { deflection } \\
{[\mathrm{mm}]}\end{array}$ & $\begin{array}{c}\text { Experimental } \\
\text { deflection } \\
{[\mathrm{mm}]}\end{array}$ \\
\hline \hline Simply support & 5.5 & 7.5 & 3.82 & 3.65 \\
\hline Cantilever & 7 & 15 & 5.87 & 5.59 \\
\hline
\end{tabular}

As observed, there is a good agreement between the results. Thus the presented approach for modeling of Young's modulus of functionally graded distribution nanocomposites has high accuracy. 


\section{Conclusions}

This paper presents the preparation with modeling and theoretical predictions of mechanical properties of functionally graded and uniform distribution polyethylene/low density polyethylene (LDPE)/modified montmorillonite (MMT) nanocomposites prepared by both solution and melt mixing techniques. From this study, the following conclusions can be made:

- The mixing technique is generally better than the solution one for preparation of the polyethylene/low density polyethylene (LDPE)/modified montmorillonite (MMT) nanocomposites.

- The compatibilizer plays an important role in improving the properties of polyethylene/low density polyethylene (LDPE)/modified montmorillonite (MMT) nanocomposites.

- By increasing weight fractions of the nanoparticles, the mechanical properties increase up to 5 wt.\% nanoclay.

- The elastic modulus for FG distribution of the nanoclay is generally larger than the corresponding value for the uniform distribution of the nanoclay.

- GA is an acceptable optimization research technique which can be used with confidence to identify mechanical properties of nanocomposites with maximum accuracy.

\section{References}

1. Avila A.F., Donadon L.V., Duarte H.V., 2008, A modal analysis of nanoclay-epoxy-fiber glass composite, Composite and Structure, 83, 324-333

2. Avila A.F., Duarte H.V., Soares M.I., 2006, The nanoclay influence on impact response of laminate plates, American Journal of Solids and Structures, 37, 3-20

3. Awaji H., Nishimura Y., Choi S., Takahashi Y., Goto T., Hashimoto S., 2009, Toughening mechanism and frontal process zone size of ceramics, Journal of the Ceramic Society of Japan, 117, $623-629$

4. Brown D., Mele P., Marceau S., 2003, A molecular dynamics study of a model nanoparticle embedded in a polymer matrix, Macromolecules, 36, 1395-1406

5. Chen L., Chen G., 2009, Relaxation behavior study of silicone rubber crosslinked network under static and dynamic compression by electric response, Polymer Composites, 30, 101-106

6. Chen X.L., Liu Y.J., 2004, Square representative volume elements for evaluating the effective material properties of carbon nanotube-based composites, Computational Materials Science, 29, $1-11$

7. Dong Y., Bhattacharyya D., Hunter P.J., 2008, Experiental characterisation and objectoriented finite element modeling of polypropylene/organoclay nanocomposites, Composite Science Technology, 68, 2864-2875

8. Einstein A., 1956, Investigation on Theory of Brownian Motion, New York, Dover

9. Eshelby J.D., 1961, Elastic inclusions and inhomogeneities, Progress in Solid Mechanics, 2, 89-140

10. Fornes T.D., Paul D.R., 2003, Modeling properties of nylon 6/clay nanocomposites using composite theories, Polymer, 44, 4993-5013

11. Grigoriadi K., Giannakas A., Ladavos A., 2012, Thermomechanical behavior of polymer/layered silicate clay nanocomposites based on unmodified low density polyethylene, Polymer Engineering Science, 51, 301-308

12. Guth E., 1945, Theory of filler reinforcement, Journal of Applied Physics, 16, 20-25 
13. Han Y., Wang Z., Li X., Fu J., Cheng Z., 2001, Polymer-layered silicate nanocomposites: synthesis, characterization, properties and applications, Current Trends in Polymer Science, 6, 1-16

14. Haque A., Shamsuzzoha M., 2003, S2-glass/epoxy polymer nanocomposites manufacturing, structures, thermal and mechanical properties, Journal of Composite Materials, 37, 1821-1837

15. Holland J.H., 1975, Adaptation in Natural and Artificial Systems, University of Michigan press, Ann Arbor

16. Hotta S., Paul D.R., 2004, Nanocomposites formed from linear low density polyethylene and organoclays, Polymer, 45, 7639-7654

17. Hrachova J., Komadel P., Moskova D.J., 2013, Properties of organo-clay/natural rubber nanocomposites, Journal of Apply Polymer Science, 127, 3447-3455

18. ISIK I., Yilmazer U., Bayram G., 2003, Impact modified epoxy/montmorillonite nanocomposites, synthesis and characterization, Polymer, 44, 6371-6377

19. Kawasumi M., Hasegawa N., Kato M., Usuki A., Okada A., 1997, Preparation and mechanical properties of polypropylene-clay hybrids, Macromolecules, 30, 6333-6338

20. Kim P.N., Doss M., Tillotson J.P., 2009, High energy density nanocomposites based on surface-modiied BaTiO3 and a ferroelectric polymer, ACS Nano, 3, 2581-2592

21. Kornmann X., Lindberg H., Berglund L.A., 2001, Synthesis of epoxy-clay nanocomposites: inluence of the nature of the clay on structure, Polymer, 42, 1303-1310

22. LiU Y.J., CHen X.L., 2003, Evaluations of the effective material properties of carbon nanotubebased composites using a nanoscale representative volume element, Mechanics of Materials, 35, 69-81

23. Nam P.H., Maiti P., Oкамото M., 2001, Hierarchical structure and properties of intercalated polypropylene/clay nanocomposite, Polymer, 42, 9633-9640

24. Pakdaman A.S., Morshedian J., Jahani Y., 2013, Effect of organoclay and silane grafting of polyethylene on morphology, barrierity, and rheological properties of HDPE/PA6 blends, Journal of Apply Polymer Science, 127, 1211-1220

25. Shen H.S., 2009, Nonlinear bending of functionally graded carbon nanotube reinforced composite plates in thermal environments, Composite Structures, 91, 9-19

26. SHEN H.S., 2011, Postbuckling of nanotube-reinforced composite cylindrical shells in thermal environments. Part I: Axially-loaded shells, Composite Structures, 93, 2096-2108

27. Shen H.S., Xiang Y., 2012, Nonlinear vibration of nanotube-reinforced composite cylindrical shells in thermal environments, Computer Methods in Applied Mechanics and Engineering, 213, 196-205

28. Sheng N., Boyce M.C., Parks D.M., Rutledge G.C., Abes J.I., Cohen R.E., 2004, Multiscale micromechanical modeling of polymer/clay nanocomposites and the effective clay particle, Polymer, 45, 487-506

29. Sмith G.D., Bedrov D., Li L., 2002, A molecular dynamics simulation study of the viscoelastic properties of polymer nanocomposites, Journal of Chemical Physics, 117, 9478-9489

30. Song S.Y., Youn J.R., 2006, Modelling of effective elastic properties of polymer based carbon nanotube composites, Polymer, 47, 1741-1748

31. TAN H., YAng W., 1998, Toughening mechanisms of nano-composite ceramics, Mechanics of Materials, 30, 111-123

32. TAndon G.P., Weng G.J., 1984, The effect of aspect ratio of inclusions on the elastic properties of unidirectionally aligned composites, Polymer Composites, 5, 327-333

33. TAYA M., 1981, On stiffness and strength of an aligned short-fiber reinforced composite containing penny- shaped cracks in the matrix, Journal of Composite Materials, 15, 198-210 
34. TAYa M., Mura T., 1981, On stiffness and strength of an aligned short-fiber reinforced composite containing fiber-end cracks under uni-axial applied stress, ASME Journal of Applied Mechanics, 48, 361-367

35. Thilly L., Petegem S.V., Renault P.O., 2009, A new criterion for elastio-plastic transition in nanomaterials. Application to size and composite effects on $\mathrm{Cu}-\mathrm{Nb}$ nanocomposite wires, Acta Materialia, 57, 3157-3169

36. Utracki L.A., Kamal M.R., 2002, Clay-containing polymeric nanocomposites, Arabian Journal for Science and Engineering, 27, 43-67

37. Yaghoobi H., Fereidoon A., 2010, Influence of neutral surface position on deflection of functionally graded beam under uniformly distributed load, World Applied Sceince Journal, 10, 337-341

38. Zhао K., He K., 2006, Dielectric relaxation of suspensions of nanoscale particles surrounded by a thick electric double layer, Physical Review B, 74, 1-10

Manuscript received June 16, 2016; accepted for print December 5, 2016 